Gut, 1986, 27, 41-48

\title{
Severe chronic constipation of young women: 'idiopathic slow transit constipation'
}

\author{
D M PRESTON AND J E LENNARD-JONES
}

From St Mark's Hospital, London

SUMMARY A series of 64 women complaining of severe constipation is described, in each of whom delayed elimination of markers from the colon was demonstrated but a barium enema was normal. All completed a detailed questionnaire and the responses are compared with those obtained in an age-matched series of healthy women with no bowel complaint. In each group 40 women also recorded in a manner suitable for analysis all food eaten over a period of seven days. The patients passed about one stool weekly with the aid of laxatives, and were greatly troubled by abdominal pain, bloating, malaise and nausea, to the extent that the symptoms were a major social disability and many lost time from work. Decreased bowel frequency and other symptoms were often first noticed around the age of puberty and slowly became worse until they were severe by the third decade. In a few, the symptoms began suddenly after an abdominal operation or accident. Comparison with the control group showed no evidence that the patients had been underweight at any time or that they took less fibre; treatment with a bran supplement did not usually help them. The patients experienced rectal sensation before defaecation less often than the control subjects and they used digital pressure to assist defaecation more frequently. The women with constipation tended to have more painful and irregular menstrual periods, and there was an increased incidence of ovarian cystectomy and hysterectomy. Hesitancy in starting to pass urine was more common, as were some somatic symptoms such as cold hands or blackouts. Attention is drawn to this distinctive combination in young women of slow total gut transit time and a colon of normal width on barium enema, associated with abdominal, anorectal, gynaecological and somatic symptoms, as a disorder which can be disabling and particularly difficult to treat.

Arbuthnot Lane's astute clinical observations appear to have been forgotten. In 1909, he described a syndrome ${ }^{1}$ of 'chronic intestinal stasis', almost confined to women, the majority of whom were under 35 . He also noticed that they tended to have poor peripheral circulation, abdominal bloating, infertility, amenorrhoea, loss of female secondary sexual characteristics, and an increased incidence of ovarian cysts.

During studies of patients complaining of constipation we became aware of a group of young women with intractable symptoms. Our findings in a series of such patients, compared with a control group, described in this paper confirm independently many of Lane's observations. This syndrome, which we

Address for correspondence: Professor J E Lennard-Jones, St Mark's Hospital, City Road, London EC1V 2PS.

Received for publication 6 March 1985 term 'idiopathic slow transit constipation', has remained largely unrecognised, perhaps because Lane's later writings were not generally accepted.

\section{Methods}

\section{PATIENTS}

ASCERTAINMENT OF CASES

A simple method, using radio-opaque solid markers for the measurement of whole gut transit rate, ${ }^{2}$ enables patients who complain of constipation to be separated into those with a normal transit rate, who pass 16 of 20 markers within five days, and the remainder with delayed elimination of the markers. During the years 1969-82, 75 patients with delayed transit, but a normal barium enema, ${ }^{3}$ presented to St Mark's Hospital with a complaint of severe chronic constipation. Of the 75 patients, 39 were still 
attending the hospital. Contact with the remaining 36 who were no longer attending was made by letter or telephone. Details about all the patients were available from hospital records. None was helped by simple dietary and laxative therapy, and no cause for their delayed intestinal transit was apparent on routine clinical or laboratory investigation. In all cases manometric studies showed a normal rectoanal distension reflex excluding congenital aganglionosis.

All 75 patients were requested to complete a questionnaire and the 64 who did so form the group described in this paper. Study of the hospital notes and available information obtained by letter and telephone did not reveal any obvious differences between the 11 who failed to complete the questionnaire and those who did so; it therefore seems likely that the 64 questionnaires analysed are representative of all the 75 patients seen over 14 years.

\section{CONTROL GROUP}

Healthy white women approached randomly in the community were invited to complete the questionnaire. From a direct approach to residents of council flats in north east London 20 women were recruited. A further 20 women agreed to participate when approached via toddler groups and similar organisations in south east London. Through acquaintances, 10 university students collaborated in Edinburgh and London. Finally, to complete an age-matched control group, so that there were equal numbers of patients and controls in the decades 16-25, 26-35, $36-45$, and $46-55,14$ women of appropriate age were found who agreed to help among hospital staff, their friends or relatives. The mean age of the patient group was $30.4 \pm 1.0$ (SEM) years and of the control group $30.9 \pm 1 \cdot 1$ years. To preserve anonymity, details of occupation, social class, and marital status were not included in the questionnaire for the control group.

Each person approached was asked if she suffered from any bowel disorder or was attending a doctor for a bowel complaint (including piles), and only those who answered 'no' were included. No other questions were asked about bowel history or gynaecological problems, and no help was given in completing the questionnaire.

\section{NUTRITION AND DIET}

Ideal weight for height was taken from standard tables ${ }^{4}$ assuming the subjects to be of medium build.

Patients and control subjects were asked to keep a complete record of all food eaten for seven consecutive days; 40 patients (none of whom had undergone colectomy) agreed to do so and they were matched with 40 control subjects who also offered to keep the necessary records. All food and drink consumed was recorded on special tables. This has previously been shown to be a more reliable method of assessing dietary intake than taking a dietary history. ${ }^{56}$ Food was not weighed because of the impossibility of obtaining compliance. An estimate of quantity was obtained by use of simple instructions about household measures and each subject was given advice on completion of the tables and asked to remain on their normal diet. The dietary records were analysed without knowledge of whether they came from a patient or a control subject by a dietitian, using the published analyses of Paul and Southgate.

\section{STATISTICAL METHODS}

Significance of differences was tested by the $\chi^{2}$ test on absolute numbers using Yates correction, Fisher's exact test or Student's $t$ test.

\section{Results}

\section{CLINICAL DETAILS}

All the patients were white women. The age at which they first remembered a bowel problem, at which they first consulted a doctor and first attended a hospital is shown in Table 1 . It will be seen that the age of onset varied widely but the onset of symptoms was generally before the age of 20 .

The first symptoms were 'constipation' (33), abdominal pain (22), 'bloating' (six) and occasionally rectal bleeding (two) or anal pain (one). The major complaint was of infrequent defaecation and the number of bowel actions per week generally decreased with the passage of years so that as a child most remembered normal bowel function but as a teenager two to three stools weekly and after the age of 20 only one stool weekly. The onset of symptoms was gradual in 54 patients but sudden in 10; this sudden onset followed appendicectomy in four, hysterectomy in four, a fall with severe injury to the perineum in one and no recognisable event in only

Table 1 Ages at which patients first experienced symptoms, consulted their doctor and were referred to hospital

\begin{tabular}{lllllllll}
\hline \multicolumn{7}{c}{ Age $(y r)$} \\
\cline { 2 - 8 } & $0-5$ & $6-10$ & $11-15$ & $16-20$ & $21-25$ & $26-30$ & $31-40$ & $>40$ \\
\hline $\begin{array}{l}\text { Onset of } \\
\text { symptoms }\end{array}$ & 15 & 6 & 16 & 16 & 8 & 1 & 2 & 0 \\
$\begin{array}{l}\text { Consulted } \\
\text { doctor }\end{array}$ & 6 & 4 & 11 & 22 & 14 & 5 & 2 & 0 \\
$\begin{array}{l}\text { Referred to } \\
\text { hospital }\end{array}$ & 0 & 3 & 7 & 16 & 21 & 5 & 7 & 5 \\
\hline
\end{tabular}


one. Half the patients remembered being given laxatives before the age of 10 .

Most of the patients regarded themselves as greatly disabled by their symptoms. Three quarters (46) had lost time from work and one fifth (12) had lost a job as a direct result of their illness. The majority (50) said that their leisure time was spoilt. The symptoms which caused this disablement were a general sense of malaise $(92 \%)$, abdominal swelling $(88 \%)$, abdominal pain $(86 \%)$, nausea $(58 \%)$ and the effect of laxatives $(46 \%)$. In many cases their lives appeared to be dominated by their abdominal and defaecatory symptoms. General enquiry suggested an abnormally high incidence of gynaecological and urinary problems. These symptoms will be discussed in relation to a control group.

In all patients symptoms had been present for many years. At the time of the questionnaire, eight patients had undergone colectomy. Of the remaining 56, only eight had spontaneous bowel actions, 42 stated that their bowels only moved in response to an oral laxative, three relied on enemas and three relied on evacuant suppositories. Of the 64 patients, 35 felt that their symptoms were getting worse, 19 considered that their condition was static and only 10 thought that they were getting better or had been cured (four of whom had been treated surgically). Most patients had taken at various times all known types of laxative. Sometimes there was initial benefit but usually the response seemed to decrease over weeks or months until it became ineffective. In some cases very large doses of stimulant laxatives were taken regularly to achieve a bowel action. The ineffectiveness of laxative therapy was striking and half the patients said that they had derived no benefit from medical treatment. This normally included lactulose, magnesium sulphate, and stimulant laxatives such as anthracene preparations or bisacodyl given by mouth or by enema.

On physical examination the patients usually looked well. The abdomen was sometimes bloated due to a lumbar lordosis with tipping forward of the pelvis and contraction of the erector spinae muscles. This bloating could be so marked as to simulate pregnancy, it was involuntary and relaxation was not possible at will. Faecal masses were not palpable in the abdomen and there was no excess gas on percussion (or on abdominal radiograph). On anorectal examination there was no evidence of soiling of the perineal skin. The tone of the internal anal sphincter and voluntary contraction of the external anal sphincter and puborectalis muscle appeared normal. The rectum was often empty and there was no faecal impaction of the rectum. Sigmoidoscopy sometimes revealed small hard stools, the rectal ampulla appeared of normal size, only rarely were the changes of melanosis coli seen.

COMPARISON WITH A HEALTHY CONTROL GROUP BOWEL FUNCTION AND ASSOCIATED SYMPTOMS (a) Bowel function

The mean number of bowel actions weekly in the control group was $6 \cdot 8 \pm 0 \cdot 4$ compared with $1 \cdot 0 \pm 0 \cdot 2$ $(p<0.001)$ among the patients (Figure). The consistency of the stools was described as 'hard' by 37 of 56 patients (excluding those who had undergone colectomy) as compared with 17 of 64 control subjects. Straining at defaecation was significantly more common among the patients than among the controls.

It has been suggested that patients with constipation lack appreciation of a bolus in the rectum and thus experience a call to stool only as an abdominal sensation. Replies to a question about how the subject knew when to open her bowels (Table 2) showed that rectal sensation was less common but still occurred in about half the patients as compared with over $80 \%$ among controls.

Almost all the control subjects $(97 \%)$ said that they passed flatus apart from bowel actions but almost one fifth of the patients (19\%) never did so $(\mathrm{p}<0 \cdot 02)$.

\section{(b) Anorectal symptoms}

The need sometimes to assist defaecation by digital pressure in the vagina or the rectum was reported by
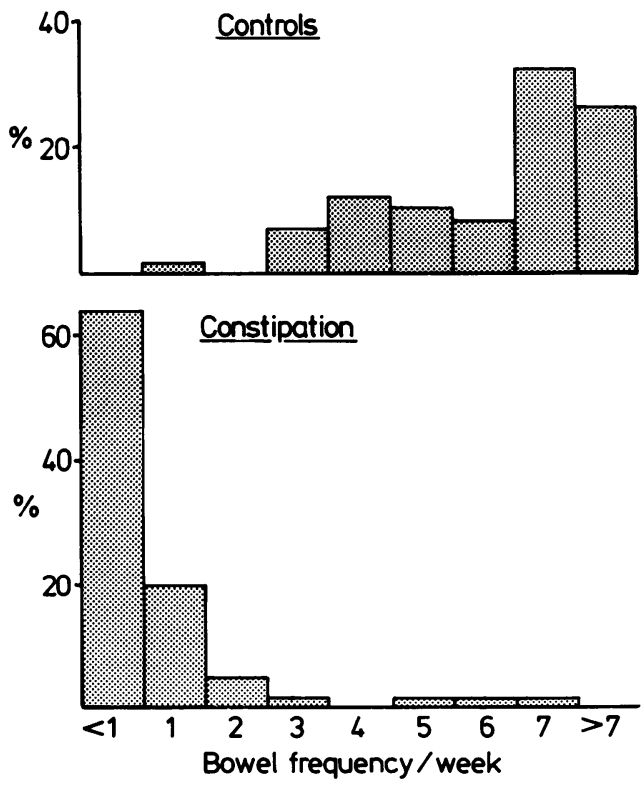

Figure Bowel frequency in the patient and control groups. 
Table 2 Sensation at the time of defaecation in the control and patient groups and the occurrence of anorectal symptoms in the two groups

\begin{tabular}{lcc}
\hline & Control (64) & Patients (64) \\
\hline Abdominal sensation & 8 & 25 \\
Rectal sensation & 50 & 15 \\
Both & 6 & 18 \\
No sensation at all & - & 6 \\
Rectal bleeding & 10 & 33 \\
Prolapse & 11 & 28 \\
Digital replacement of prolapse & 5 & 18 \\
\hline
\end{tabular}

nine of the control subjects and 26 of the patients $(p<0 \cdot 01)$. Several anorectal symptoms had occurred in both groups but were more common among the patients (Table 2).

The symptom of bloating was very common among the patients (54 of 64 ) but also surprisingly occurred in half $(32)$ the controls $(\mathrm{p}<0 \cdot 001)$. This symptom was first noted at about the age of 20 in both groups. One quarter of the patients, but only $10 \%$ of the controls experienced a constant sense of bloating $(p<0 \cdot 05)$, others associated its onset with food or the menstrual period.

(c) Abdominal symptoms

A large number of the patients (49) experienced abdominal pain in relation to defaecation but only nine controls $(p<0.001)$.

\section{NUTRITION AND DIET}

(a) Nutrition

Each woman was asked to record her present weight, her height, and also her maximum and minimum weight at any time. The results (Table 3) do not suggest that significant undernutrition was ever present in either group.

\section{(b) Diet}

Analysis (Table 4) of the seven day dietary records showed no difference as regards fibre intake but the control subjects took slightly more carbohydrate

Table 3 Body weight reported by patients and control subjects expressed as percentage of ideal weight at the time of the questionnaire, and the minimum and maximum weights at any time in adult life (mean $\pm S E M$ )

\begin{tabular}{lcc}
\hline Ideal weight (\%) & Controls & Patients \\
\hline Present & $108 \pm 2$ & $101 \pm 2$ \\
Maximum & $117 \pm 4$ & $111 \pm 3$ \\
Minimum & $95 \pm 1$ & $90 \pm 1$ \\
\hline
\end{tabular}

Table 4. Results of dietary assessment of the main dietary constituents (mean daily intake over seven consecutive days) in the patient and the control groups (mean $\pm S E M$ )

\begin{tabular}{lccl}
\hline Daily intake & Control & Patients & $p$ \\
\hline Fluid (ml) & $1208 \pm 60$ & $1234 \pm 77$ & NS \\
Fibre (G) & $15 \pm 0 \cdot 6$ & $14 \cdot 7 \pm 0 \cdot 7$ & NS \\
Sugar (G) & $33 \pm 3$ & $33 \pm 3$ & NS \\
Total carbohydrate (G) & $172 \pm 8$ & $156 \pm 10$ & $<0 \cdot 01$ \\
Fat (G) & $91 \pm 3$ & $90 \pm 3$ & NS \\
Protein (G) & $50 \pm 1$ & $49 \pm 2$ & NS \\
Total calories & $1728 \pm 56$ & $1613 \pm 72$ & $<0.02$ \\
\hline
\end{tabular}

$(p<0.01)$ and total calories $(p<0.02)$ than the patients.

The majority of patients with constipation (84\%) said that they had changed their diet since the onset of symptoms, usually because of dietary advice, but sometimes because of pain. Two thirds of the patients $(69 \%)$ said that they ate less than they used to do and about half of them attributed their lower food intake to nausea or anorexia. One third of the control subjects and most $(91 \%)$ of the constipated patients had tried a regular bran supplement or a high fibre diet $(\mathrm{p}<0.001)$. Most of these control subjects (16 of 21) reported that the supplement made defaecation easier and/or more frequent. In contrast only nine of 58 patients stated that bran had this beneficial effect, 49 said that it had no effect or actually made the symptoms worse $(p<0.001)$.

Specific food sensitivities were complained of more commonly (15\%) among the control subjects than among the patients (3\%). In both groups about one third of the women had put themselves on a diet for a period of five to seven months for one reason or another during their lives.

\section{GYNAECOLOGICAL, OBSTETRIC AND BREAST PROBLEMS}

\section{(a) Menstruation}

One third (21) of the control subjects and 11 of the patients were taking the contraceptive pill at the time of the questionnaire (NS). About two thirds of the women in both groups had, however, taken the contraceptive pill at some time. When taking the pill, there was no obvious effect on bowel habit in either group.

Menstruation tended to be irregular more commonly $(45 \%)$ among the patients than among the controls $(20 \%)$ when not taking the pill. Three quarters of the subjects in both groups who were menstruating were troubled by painful periods and of these pain limited activities in 26 of 42 patients $(59 \%)$ and 10 out of 46 controls $(p<0.001)$. About one third (15) of these patients had consulted their 
doctor about painful periods as compared with only four controls $(p<0.005)$.

There was no constant effect of the menstrual period on bowel habit in either group, about one fifth were more constipated than usual, half noticed no change and one third noticed easier or more frequent bowel actions.

\section{(b) Pregnancy}

Just over half the women in both groups had been pregnant and about one third of them had experienced a miscarriage. The obstetric history as regards caesarian section, or other complications showed no differences. About one quarter (18) of the patients experienced difficulty in starting a pregnancy as compared with six in the control group $(p<0.02)$.

The effect of pregnancy on the bowel habit was variable and did not differ significantly in the two groups. About one fifth of the constipated women regarded their bowel habit as better after pregnancy than before.

\section{(c) Gynaecological problems}

Dyspareunia and/or anorgasmia occurred in about one third of the patients and about one fifth of the controls (NS). The proportion of patients having a gynaecological operation (other than termination, sterilisation, D \& C or caesarian section) was significantly higher $(\mathrm{p}<0.001)$ among the patients (26) than the controls (six). Ovarian cystectomy and hysterectomy were the most common non-obstetric procedures among the patients. The mean number of gynaecological/obstretric operation per patient was $1 \cdot 3 \pm 0.2$ compared with $0 \cdot 6 \pm 0 \cdot 2$ per control subject $(\mathrm{p}<0.05)$.

\section{(d) Breast symptoms}

Breast lumps $(9 \%)$ or nodularity $(31 \%)$ were reported rather more frequently among the patients (NS). A discharge of milk from the breast unassociated with pregnancy was noted by seven of the patients and only one of the control women (NS).

\section{OTHER SYMPTOMS}

\section{(a) Urinary symptoms}

There was no difference in frequency of micturition by day between the two groups but more of the patients $(42 \%)$ than the controls $(21 \%)$ reported nocturia $(p<0.02)$ and significantly more $(p<0.001)$ complained of difficulty in starting to pass urine ( $25 \%$ as compared with $2 \%$ ).

\section{(b) Cold hands}

Pale cold fingers in response to cold were significantly $(\mathrm{p}<0.001)$ more common among patients $(37)$ than controls (12) and more of the patients (nine) than the controls (two) had consulted their doctor about this problem, perhaps because cold fingers were noticed in summer more often by patients (12) than the healthy subjects (six).

\section{(c) 'Blackouts' or epilepsy}

'Blackouts' had occurred in 14 of the patients as compared with only one of the controls $(\mathrm{p}<0.0005)$. A diagnosis of epilepsy had been made in seven of the patients but none of the controls $(p<0.02)$.

\section{FAMILY HISTORY}

All subjects were asked about the occurrence of a number of different disorders in the family. There was no difference in the frequency of asthma, arthritis, migraine, or epilepsy among the families of the two groups. There was no significant excess of constipation in the families of the patients, and specifically among the mothers or sisters, though there was a trend to an increased frequency (patients 33, controls 23). One member each of two pairs of identical twins were included among the patients; in both cases the other twin was normal.

\section{ILLNESS BEHAVIOUR}

Previous studies have suggested that patients with functional bowel disorders visit their doctor more frequently with various somatic complaints than healthy subjects or patients with peptic ulcer. ${ }^{89}$ Both the control subjects and the patients had attended their general practitioner with an upper respiratory illness on about three occasions in the previous five years (NS). Patients complained rather more often $(22 \%)$ than controls $(9 \%)$ of frequent colds or 'flu (NS).

\section{SURGICAL TREATMENT (Table 5)}

The patients had undergone appendicectomy $(\mathrm{p}<0.01)$, hysterectomy $(\mathrm{p}<0.01)$ and ovarian cystectomy $(p<0.005)$ significantly more often than the control group but not more non-abdominal procedures.

Table 5. Number of women who had undergone surgical procedures in the patient and control groups

\begin{tabular}{llll}
\hline Operation & Controls & Patients & $p$ \\
\hline Appendicectomy & 12 & 28 & $<0.01$ \\
Colectomy for & & & \\
$\quad$ constipation & - & 8 & $<0.01$ \\
Hysterectomy & 2 & 12 & $<0.005$ \\
Ovarian cystectomy & 2 & 14 & NS \\
Non-abdominal & 28 & 24 & \\
\hline
\end{tabular}




\section{Discussion}

St Mark's is a hospital which specialises in colorectal disorders. There is no paediatric department and almost all patients referred are over the age of 14 years. They come from a wide area, over half from outside greater London. A disproportionately high number of adult patients who present difficult problems in diagnosis or treatment are therefore seen and the patients described in this paper thus tend to represent a group with particularly severe and intractable symptoms.

The way in which these patients were selected eliminated those who responded to simple treatment and those with a normal transit rate through the gut. In every case, delayed evacuation of radio-opaque markers provided objective evidence of a slow transit rate, and a barium enema excluded megacolon or other anatomical abnormality. The group so defined proved to be all women who passed about one stool a week with the aid of laxatives, and who were greatly troubled by abdominal pain, bloating, malaise and nausea, to the extent that many lost time from work and their social life was spoilt. As might be expected, anorectal symptoms such as hardness of the stools, anal pain, rectal bleeding, and prolapse were also common among them.

A survey among workers at a factory who were not seeking medical advice revealed that seven out of 655 women, but none of 400 men, reported a bowel frequency of two stools weekly or less. ${ }^{10}$ It is thus possible that constipation occurs in about $1 \%$ of normal women. The patients described in this series had much more troublesome symptoms than any of the women in the factory community. We do not know whether our patients represent a very severe form of a physical disorder or an exaggerated response to a common symptom. Decreased bowel frequency and other symptoms were usually first noticed around the age of puberty and slowly became worse until they were often severe and disabling by the third decade. Sometimes the symptoms began suddenly after an abdominal operation or an accident. Why were these patients troubled in this way and why were they all women?

Mild symptoms of reduced bowel frequency or difficulty in defaecation can be due to a deficient intake of fibre. This survey suggests that the patients and a control group with normal bowel habit took the same amount of fibre. It is recognised that dietary surveys, especially when conducted by post are subject to great error and difficulties of interpretation. The blind assessment by the dietitian in the present study, however, makes it likely that a consistent bias was avoided and that errors were spread evenly between the two groups. There was also no evidence from the survey to suggest that these women had greatly restricted their food intake at any stage of their life, nor were they undernourished. In 1902, Goodhart suggested, ${ }^{11}$ and later investigation has confirmed, that some people digest dietary residue more thoroughly than others. ${ }^{12}$ The colonic bacterial flora in these patients may break down fibre more completely than normal so reducing the fibre component of the stool, or the flora may exhaust the substrate and fail to proliferate so reducing the bacterial component of the stool. ${ }^{12}$ The reason why these patients were sometimes made worse, and were certainly not helped by a bran supplement is unexplained.

Pressure $^{13-18}$ and electrical potential ${ }^{1920}$ recordings suggest that there may be a functional abnormality of the colon associated with constipation. Recordings of motor activity have not given a clear answer possibly because there is great variability from time to time and between patients. ${ }^{21}$ Anatomical evidence of a colonic abnormality comes from examination of the myenteric nerve plexus by silver staining in patients treated surgically for constipation. Two studies ${ }^{22}{ }^{23}$ have shown disorganisation of the plexus in some patients with an otherwise apparently normal colon, but this abnormality could be due to the prolonged use of laxatives rather than the original cause of symptoms. It can be argued that the progression of symptoms in these patients might have been because of increasing dependence on laxatives which in turn caused symptoms and colonic damage but no information is available on this point.

There is increasing evidence that abnormal function of the striated pelvic floor muscle can lead to difficulty in defaecation as originally suggested in 1910 by Beddard. ${ }^{24}$ Patients such as those described here cannot expel a balloon from the rectum, a test used as an experimental model of defaecation, and during attempted expulsion the puborectalis and external sphincters contract instead of relaxing normally. ${ }^{25}{ }^{26}$ Sustained contraction of the puborectalis maintains the normal angle between the rectum and anal canal and so prevents the alignment of the channels necessary for passage of a stool. During normal defaecation the pelvic floor relaxes, it descends and the anorectal angle widens. ${ }^{27-29}$ Digital pressure on the puborectalis might straighten this angle and it is therefore interesting that some women in both the control and patient groups, but more in the latter, used digital pressure to assist defaecation.

There is suggestive evidence that many patients with constipation but without obvious megarectum fail to appreciate small volumes of up to $50 \mathrm{ml}$ in a rectal balloon whereas this volume is felt by all 
normal adults; ${ }^{30}$ similar results have been obtained in children. ${ }^{31}$ The survey did show that about half the patients with constipation felt no rectal sensation as compared with one fifth of the control subjects.

Women with constipation tended to have more painful and irregular menstrual periods than the control subjects. Some of them said that their only spontaneous bowel actions occurred during a period. There was also a higher incidence of ovarian cystectomy, hysterectomy and galactorrhoea among the patients as noted in other reports. ${ }^{32-34}$ It seems possible that an abnormality of sex hormone secretion affects the gut or, conversely, that the enterohepatic circulation of oestrogens is affected by an abnormality of the intestine.

The increased incidence of hesitancy in starting to pass urine, and of Raynaud's phenomenon, among the patients as compared with controls could indicate a widespread autonomic disturbance. A sensory defect to bladder distension has been noted among some patients with constipation..$^{32}$ It is also possible that some of these patients find it difficult to relax not only the external anal sphincter on defaecation but also the external urethral sphincter on passing water.

People with irritable bowel syndrome are more likely than the general population to have multiple somatic complaints and to consult a doctor more often for minor illnesses, ${ }^{8}$ though these traits tend to occur among patients complaining of abdominal pain rather than among patients with reduced bowel frequency. ${ }^{9}$ Whether or not the type of constipation decribed in this paper is a particular form of the irritable bowel syndrome in young women can be determined only when the mechanisms of functional bowel symptoms are better understood. There was little evidence from this survey of unusual illness behaviour among our patients. There was also no evidence of a family history of constipation among the patients so that bowel consciousness in early life cannot be attributed to this cause. It seems likely that the high frequency with which laxatives were taken before the age of 10 was due to the onset of symptoms, rather than the reverse. A striking feature of this type of constipation is its resistance to treatment. The failure of fibre and bulk laxatives has already been described. Stimulant laxatives such as bisacodyl or anthracene derivatives tend to lose their potency and when they cause a bowel action it tends to be loose, urgent and associated with much pain. Similarly, osmotic laxatives such as magnesium sulphate tend to be ineffective until the stools become liquid and even these may be difficult to expel.

The patients resented any implication that their symptoms were psychologically determined. In a separate study psychometric questionnaires showed that they differed little from other patients with a structural bowel disorder of comparable severity. ${ }^{35}$ A detailed psychological history, however, often suggested an unusually high incidence of unhappy childhood and/or psychosexual problems. The data in this survey showed a wide range of somatic disabilities such as restricted activity from painful periods, cold hands, blackouts, and a tendency to frequent colds or 'flu. It is not clear whether these symptoms were because of physiological or psychological disorder. Further controlled psychological evaluation is required.

Constipation is often regarded as a trivial symptom but for the patients described here it was a major disability. Some were so disabled that partial or total colectomy was undertaken; results in these 21 patients are described elsewhere. ${ }^{36}$ Such a severe disorder deserves more research into its aetiology and treatment.

We thank Miss E Rogers for her help in the diet questionnaire. Dr D M Preston was supported by the St Mark's Research Foundation. We thank all the patients and the control subjects for their help and enthusiasm.

\section{References}

1 Lane WA. Chronic intestinal stasis. Br Med J 1909; 1: 1408-11.

2 Hinton JM, Lennard-Jones JE, Young AC. A new method for studying gut transit time using radio opaque markers. Gut 1969; 10: 842-7.

3 Preston DM, Lennard-Jones JE, Thomas BM. Towards a radiological definition of idiopathic megacolon. Gastrointest Radiol 1985; 10: 167-9.

4 Statistical Bulletin of the Metropolitan Life Insurance Co. 1959; 40.

5 Young CM, Hagan GC, Tucker RE, Foster WD. A comparison of dietary study methods 2 . Dietary history vs Seven-day Record vs $24 \mathrm{Hr}$ Recall. J Am Diet Assoc 1952; 28: 218-21.

6 Marr JW. Individual dietary surveys: purposes and methods. World Rev Nutr Diet 1971; 13: 105-64.

7 Paul AA, Southgate DAT. The composition of foods. London: HMSO, 1978.

8 Whitehead WE, Winget C, Fedoravicius AS, Wooley $\mathrm{S}$, Blackwell B. Learned illness behaviour in patients with irritable bowel syndrome and peptic ulcer. Dig Dis Sci 1982; 27: 202-8.

9 Sandler RS, Drossman DA, Nathan HP, McKee DC. Symptom complaints and health care seeking behaviour in subjects with bowel dysfunction. Gastroenterology 1984; 87: 314-8. 
10 Connell AM, Hilton C, Irvine G, Lennard-Jones JE, Misiewicz JJ. Variation of bowel habit in two population samples. Br Med J 1965; 2: 1095-9.

11 Goodhart JF. Round about constipation. Lancet 1902; 2: 1241-6.

12 Cummings JH. Constipation, dietary fibre and the control of large bowel function. Postgrad Med J 1984; 60: 811-9.

13 Connell AM. The motility of the pelvic colon. Part II. Paradoxical motility in diarrhoea and constipation. Gut 1962; 3: 342-8.

14 Meunier P, Rohas A, Lambert R. Motor activity of the sigmoid colon in chronic constipation: comparitive study with normal subjects. Gut 1979; 20: 1095-101.

15 Preston DM, Lennard-Jones JE. Does failure of bisacodyl-induced peristalsis indicate intrinsic nerve damage? Dig Dis Sci 1985; 30: 289-94.

16 Waller SL, Misiewicz JJ. Colonic motility in constipation or diarrhoea. Scand J Gastroenterol 1972; 7: 93-6.

17 Waller SL, Misiewicz JJ, Kiley N. Effect of eating on motility of the pelvic colon in constipation or diarrhoea. Gut 1972; 13: 805-11.

18 Wangel AG, Deller JD. Intestinal motility in man. III. Mechanisms of constipation and diarrhoea with particular reference to the irritable colon syndrome. Gastroenterology 1965; 48: 69-84.

19 Frieri G, Parisi F, Corazziari E, Caprilli R. Colonic electromyography in chronic constipation. Gastroenterology 1983; 84: 737-40.

20 Bueno L, Fioramonti J, Ruckebusch Y, Frexinos J, Coulom P. Evaluation of colonic myoelectrical activity in health and functional disorders. Gut 1980; 21: 480-5.

21 Dinoso VP jr, Murthy SNS, Goldstein J, Rosner B. Basal motor activity of the distal colon: a reappraisal. Gastroenterology 1983; 85: 637-42.

22 Preston DM, Butler MG, Smith B, Lennard-Jones JE. Neuropathology of slow transit constipation. [Abstract]. Gut 1983; 24: A997.

23 Krishnamurthy S, Schuffler MD, Rohrmann CA, Pope II CE. Severe idiopathic constipation is associated with a distinctive abnormality of the colonic myenteric plexus. Gastroenterology 1985; 88: 26-34.

24 Beddard AP. Secondary constipation. Practitioner 1910; 84: 610-27.

25 Preston DM, Lennard-Jones JE. Anismus in chronic constipation. Dig Dis Sci 1985; 30: 413-8.

26 Barnes PRH, Lennard-Jones JE. Patients with constipation of different types have difficulty in expelling a balloon from the rectum. Gut 1985; 26: 1049-52.

27 Fry IK, Griffiths JD, Smart PJG. Some observations on the movement of the pelvic floor and rectum with special reference to rectal prolapse. Br J Surg 1966; 53: 784-7.

28 Tagart REB. The anal canal and rectum: their varying relationship and its effect on anal continence. Dis Colon Rectum 1966; 9: 449-52.

29 Kerremans R. Morphological and physiological aspects of anal continence and defaecation. Brussels: Editions Arscia SA, 1969.

30 Baldi F, Ferrarini F, Corinaldesi R, et al. Function of the internal anal sphincter and rectal sensitivity in idiopathic constipation. Digestion 1982; 24: 14-22.

31 Meunier P, Marechal JM, De Beaujeu MJ. Rectoanal pressures and rectal sensitivity studies in chronic childhood constipation. Gastroenterology 1979; 77: 330-6.

32 Corraziari E, Bausano G, Torsoli A et al. Italian co-operative study on chronic constipation. Ital $J$ Gastroenterol 1981; 13: 279.

33 Watier A, Devroede G, Duranceau A et al. Constipation with colonic inertia: a manifestation of systemic disease. Dig Dis Sci 1983; 28: 1025-33.

34 Preston DM, Rees LH, Lennard-Jones JE. Gynaecological disorders and hyperprolactinaemia in chronic constipation. [Abstract]. Gut 1983; 24: A480.

35 Preston DM, Pfeffer JM, Lennard-Jones JE. Psychiatric assessment of patients with severe constipation. [Abstract]. Gut 1984; 25: A582-3.

36 Preston DM, Hawley PR, Lennard-Jones JE, Todd IP. Results of colectomy for severe idiopathic constipation in women (Arbuthnot Lane's disease). Br J Surg 1984; 71: $547-52$. 